\title{
USOS E INSTRUMENTALIZAÇÕES DA MEMÓRIA EM REABERTURAS DE ANTIGOS CINEMAS: DE ROMA, UM CASO BELGA
}

\section{Edição v.35} número 3 / 2016-17

Contracampo e-ISSN 2238-2577 Niterói (RJ), v. 35, n. 3

dez/2016-mar/2017

A Revista Contracampo é uma revista eletrônica do Programa de Pós-Graduação em Comunicação da Universidade Federal Fluminense e tem como objetivo contribuir para a reflexão crítica em torno do campo midiático, atuando como espaço de circulação da pesquisa e do pensamento acadêmico.

\section{INSTRUMENTAL USES OF MEMORY IN REOPENING PROJECTS OF OLDER} CINEMAS: DE ROMA, A BELGIAN CASE

\section{TALITHA GOMES FERRAZ}

Talitha Ferraz é doutora em Comunicação e Cultura pela ECO-UFRJ e realizou pós-doutorado no Centre For Cinema and Media Studies da Ghent University (CIMS-UGent). É docente na ESPM-Rio, líder do Grupo de Pesquisa Modos de Ver (ESPM/ CNPq), e pesquisadora associada à Coordenação Interdisciplinar de Estudos Contemporâneos da UFRJ (CIEC-UFRJ). Brasil.

talitha.ferraz@gmail.com

\section{PPG $\mid C O M$ comincactio UFF}

AO CITAR ESTE ARTIGO, UTILIZE A SEGUINTE REFERÊNCIA:

FERRAZ, Talitha Gomes. Usos e instrumentalizações da memória em reaberturas de antigos cinemas: De Roma, um caso belga.

Contracampo, Niterói, v. 35, n. 03, dez. 2016/ mar. 2017.

Enviado em 10 de setembro de 2015 / Aceito em: 09 de março de 2016. 


\section{Resumo}

Analisamos os usos estratégicos das memórias ligadas a antigas salas de exibição e práticas de cinemagoing por projetos de reabertura de cinemas. O foco deste trabalho é o caso do cine De Roma, localizado na Antuérpia, Bélgica, reaberto como um teatro popular por meio de um conjunto de ações da sociedade civil e instâncias governamentais locais. Com base nas representações do passado cinematográfico do equipamento e de sua imagem como forte ponto referencial local e exímio "lugar de memória", o processo de reativação do De Roma e as dinâmicas socioculturais e políticas efetivadas ao seu redor envolvem uma série de questões ligadas à gestão da "memória coletiva" das audiências. À luz do paradigma New Cinema History, cremos que o enquadramento estratégico da memória e a legitimação de determinadas versões sobre o passado do De Roma dizem respeito a esferas ligadas à organização social e do lazer locais e a dinâmicas concernentes às políticas culturais belgas. A partir disso, sugerimos que os projetos de reabertura de históricas salas de cinema precisam ser observados como peças de enredadas táticas de gestão da cultura e das memórias das audiências.

\section{Palavras-chave}

ida ao cinema; reabertura de cinemas; memória; New Cinema History

\section{Abstract}

We analyze the strategic uses of the memories related to former movie theatres and cinema-going practices by cinema reopening projects. This paper focuses on the case of the De Roma cinema, located in Antwerp, Belgium, which was reopened as a popular theatre through a series of interactions between civil society and governmental bodies. Based on the representation of the cinematic past of the equipment and its image as a strong urban landmark and a "realm of memory", the reactivation processes of the De Roma and sociocultural dynamics around it involve a range of issues concerning with the management of the audiences' collective memories. In the light of the New Cinema History paradigm, we believe that the strategic "memories framings" as well as the legitimation of particular versions about the De Roma past concern spheres connected to the local social structure and leisure practices in addition to dynamics related to the Belgian cultural policies. Based on this, we suggest the projects of reopening historical cinemas should be observed as parts of tactics to manage culture and audiences' memories.

\section{Keywords}

cinema-going; cinema reopenings; memory; New Cinema History 


\section{Introdução: um cenário de reaberturas}

Nos últimos anos, o tema sala de cinema vem ganhando destaques significantes na Bélgica em meio às dinâmicas socioculturais de algumas esferas da sociedade, às atenções da mídia e às políticas culturais implementadas pelas comunidades linguísticas/ governamentais francesa e flamenga que formam o estado pilarizado

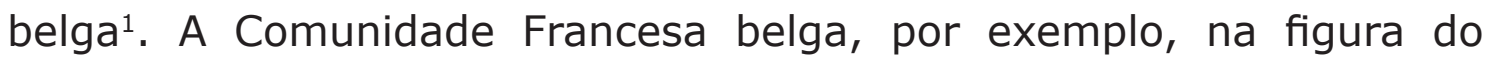
Centre du Cinéma et de l'Audiovisuel, dedica boa parte de suas atuais preocupações com o cinema nacional, incluindo nesse bojo questões como a criação de novos cinemas de arte e ensaio e a reativação de notáveis salas de exibição atualmente extintas. Em seu relatório anual de 2015, o órgão menciona a retomada dos cinemas Caméo e Le Palace, ambos antigos cinemas de rua das cidades de Namur e Bruxelas, e ressalta que iniciativas em prol da abertura de salas de exibição se ligam diretamente aos esforços para a difusão dos filmes belgas no país:

O primeiro elemento essencial é a abertura de novas salas de cinema. O ano de 2015 será um ano importante nesse aspecto. Três cinemas dedicados a filmes de arte e ensaio deverão abrir as suas portas: Le Caméo ( 5 telas) em Namur, Le Quai 10 (4 telas) em Charleroi e Le Palace (4 telas) em Bruxelas; essas 13 novas telas serão muito importantes para a difusão de nossos filmes porque elas darão a eles novas oportunidades de serem vistos por um grande público. Além disso, não há nenhuma restrição concernente à difusão de filmes belgas em salas de arte e ensaio subvencionadas. Assim, como já se pratica no setor de artes e encenações, os dispositivos contratuais serão implementados em prol dos filmes belgas (CENTRE DU CINÉMA ET DE L'AUDIOVISUEL, 2015, tradução nossa).

Em um nível paralelo a este breve exemplo concernente à esfera governamental, autores belgas ligados aos cinema-going studies, isto

1 A Bélgica é um país territorialmente dividido em três comunidades linguísticas, sociopolíticas e culturais: a Comunidade Francesa, a Comunidade Flamenga - que são mais fortes e maiores em número de cidadãos e área de abrangência - e a Comunidade Alemã. Numa segunda linha de divisão do poder estatal, estão as regiões que têm autonomias econômicas e políticas: Valônia, Bruxelas (a capital bipartida entre as comunidades francesa e flamenga) e Flandres. A ideia de pilarização, isto é, de uma sociedade que se divide verticalmente, como em pilares, pode ser aplicada a este tipo de estrutura. Cada uma das comunidades belgas tem orçamentos e instâncias governamentais independentes, que, por sua vez, não invalidam a existência do governo federal, que inclui o Parlamento e a Família Real (PORTAL BELGIUM.BE, 2012). 
é, os estudos das práticas de ida ao cinema, têm estruturado uma série de pensamentos e análises historiográficas acerca da proeminência das salas de cinema nos contextos urbanos e do papel que tais equipamentos desempenham/desempenharam na construção de uma memória da espectação cinematográfica. Isso inclui, entre outros aspectos, a verificação de como se dá ao longo do tempo a inserção dos equipamentos de exibição (presentes ou ausentes nas ruas) nos mapas afetivos e modos de lazer dos espectadores em algumas localidades da Bélgica. Essa recente corrente de estudos vinculada à história do cinema segue um caráter transdisciplinar e se inspira por aquilo que seus pesquisadores chamam de cinema culture: um domínio extenso que não desassocia a cultura cinematográfica e as práticas das audiências dos contextos sociais, econômicos, culturais e políticos locais/globais.

Tal panorama de investigação, entretanto, não se restringe ao cenário acadêmico belga e se espalha por departamentos de Cinema e Mídia de universidades de outras regiões da Europa (Holanda, Inglaterra, Escócia, Alemanha, por exemplo), além de Austrália e EUA etc. ${ }^{2}$, as análises desenvolvidas nesse âmbito, em linhas gerais, têm como foco a cultura do cinema e abraçam tudo aquilo que tangencia o equipamento sala de cinema (suas localizações nas cidades, tipos de programação e seus usos cotidianos pelas pessoas, por exemplo). Uma vasta produção de artigos e livros vem sendo produzida dentro do que os pesquisadores dessa linha batizaram como New Cinema History, paradigma que considera os cinemas muito mais do que simples espaços neutros ligados à era das velhas mídias modernas.

Segundo o New Cinema History a triangulação formada pela sala de cinema, filmes exibidos/programação e consumos das audiências foi em alto grau elipsada dentro da ortodoxia da Grande História do Cinema, que, de algum modo, preteriu essa interconexão em favor

2 A rede Homer Project - The History of Moviegoing, Exhibition and Reception, por exemplo, foi criada em 2004 para reunir pesquisadores internacionais que trabalham com estudos multidisciplinares ligados à prática de cinema-going (ida ao cinema), à exibição cinematográfica e à recepção. Disponível em: http:// homernetwork.org/about/. Acesso em: 9 out. 2015. 
das preferências pelos estudos fílmicos. Simultaneamente, também há certo incômodo desta nova corrente com o habitual dualismo conceitual e metodológico entre "texto" e "contexto" no cinema, que divorcia os estudos fílmicos/análise fílmica de seu pano de fundo industrial, cultural e histórico, e vice-versa (KUHN, 2002, p.4).

Na medida em que os estudos de cinema privilegiam o texto do filme, por exemplo, eles vão minimizar não só a recepção dos filmes pelo público, mas também os contextos social e histórico e as configurações industriais e institucionais em que os filmes são produzidos e consumidos (...). No entanto, se a análise fílmica às vezes é conduzida como se os filmes não fossem produzidos e consumidos por pessoas em determinadas épocas e lugares, os estudos da mídia e audiências baseados nas Ciências Sociais rotineiramente marginalizam os textos midiáticos, tratando-os como meros epifenômenos das suas condições de existência social, cultural ou industriais (KUHN, 2002, p.4, tradução nossa).

Um dos pontos especiais do New Cinema History é a proposta de que os equipamentos sala de cinema são peças inseparáveis de fatores econômicos, políticos, culturais, geográficos e, obviamente, cinematográficos. Além disso, nessas análises não há isolamentos entre os eixos de produção, exibição, distribuição e estruturas do consumo cinematográficos. Deste modo, por meio de variadas metodologias e métodos emprestados da etnografia, história oral, análise do discurso etc., e com apreço pela produção de bases de dados quantitativos e mapeamentos, os autores ligados ao New Cinema History desenvolvem um pensamento vigoroso sobre a sala de exibição e a cultura da ida ao cinema, em vista da vida cotidiana das audiências, da memória dos espectadores, das esferas ideológicas e de poder, do gosto, das afirmações identitárias locais etc. (BILTEREYST E MEERS, 2011; LOTZE e MEERS, 2013; MALTBY, BILTEREYST, MEERS, 2012; KUHN, 2002).

O Cinema se tornou um assunto de interesse histórico para investigadores que não foram educados pela ortodoxia profissional, para a qual o tema adequado aos estudos de cinema são os estudos fílmicos. Do ponto de vista da geografia histórica, história social, economia, estudos de antropologia ou da população, a observação de que os cinemas são espaços de importância social e cultural tem muito a ver com os padrões de emprego, o desenvolvimento urbano, os sistemas de transporte e as práticas de lazer que 
formam a difusão cinematográfica global (...). O New Cinema History oferece uma interpretação que complementa e é informada por vários aspectos da história cinematográfica, particularmente pelas investigações das condições globais de produção, das inovações técnicas e artísticas e das múltiplas e interligadas culturas organizacionais que caracterizam a indústria da produção cinematográfica. $A$ isso acrescenta o conhecimento das operações históricas das redes mundiais dos negócios de distribuição e exibição, e das formas como estas redes interligadas de interesses corporativos globais, franquias locais e outras pequenas empresas têm gerenciado conjuntamente 0 fluxo dos produtos cinematográficos nos cinemas mundiais e outros espaços. Ele [New Cinema History] usa informações quantitativas articuladas através dos aparatos de bases de dados, análise espacial e geovisualização para avançar numa série de hipóteses sobre a relação dos cinemas com agrupamentos sociais, na expectativa de que estas hipóteses sejam testadas de outras formas, qualitativas. Demostrando uma gama de materiais de arquivo próprios aos âmbitos da história operacional e institucional do cinema, o New Cinema History vai fortemente de encontro à adequação a uma história total do cinema baseada no estudo fílmico. Ao mesmo tempo, o New Cinema History oferece uma contraproposta à suposição de que o que importa no estudo sobre a experiência da audiência deve se limitar à "recepção" - isto é, ao que acontece nos momentos em que o público está principalmente focado na tela ou quando os espectadores estão pensando sobre o filme e seus possíveis significados após assisti-lo (MALTBY, 2011, p. 12 , tradução nossa).

Localizamos a nossa análise $^{3}$ justamente no rastro de tais tendências investigativas, conectando-a ao atual conjunto de discussões e ações em torno da importância das salas de cinema/ prédios da exibição para a configuração do espaço urbano. As pesquisas acadêmicas, discussões gerais e ações desenvolvidas nesse domínio têm direcionado o olhar para a intensa participação dos cinemas na produção da "memória dos lugares urbanos" (JODELET, 2010) e das memórias pessoais dos indivíduos. Aliados à consideração de que os cinemas são "espaços de importância social e cultural", cuja história operacional e institucional está articulada à experiência de audiências e

3 As discussões lançadas neste artigo vinculam-se diretamente à corrente New Cinema History e fazem parte da pesquisa "Public-Private Partnerships as a reaction to closed movie theaters: A comparative study between the suburban Cinecarioca Méier in Rio de Janeiro and Belgian cases of reopening cinemas", desenvolvida pela autora durante estágio pós-doutoral no Centre for Cinema and Media Studies da Ghent University, Bélgica, entre fevereiro de 2015 e fevereiro de 2016, no âmbito do Programa de Pesquisa Pósdoutoral no Exterior da Capes. 
agrupamentos sociais (MALTBY, 2011, p. 12), neste artigo verificaremos como procedem alguns usos e instrumentalizações da memória do cinema e das práticas de cinema-going no âmbito de um episódio bem específico de reativação de antigos cinemas da Bélgica: o caso do cine De Roma, que, após longos 20 anos de abandono, reabriu as portas em 2003 como um teatro popular.

Situado no distrito do Borgerhout, na Antuérpia, uma das regiões flamengas da Bélgica, o caso deste antigo cinema é um destaque entre as reaberturas de cinemas belgas empreendidas na contemporaneidade. A particularidade de seu processo de reativação, conforme veremos mais adiante, se deve a uma série de dinâmicas socioculturais e sociopolíticas e a determinados usos da memória que se apoiam numa rede de narrativas sobre as práticas de cinema-going efetivadas nesse espaço ao longo da segunda metade do século $X X$. Desde o início de sua recuperação, em 2002, é realizado um trabalho constante de renovação das estruturas originais do equipamento, que conta basicamente com os esforços de uma comunidade de antigos frequentadores e entusiastas. O fio condutor desses esforços é a luta pela manutenção dos vínculos do De Roma com a região do Borgerhout, tendo em vista a sustentabilidade do equipamento no presente, os traumas comunitários ligados ao longo período de seu fechamento e o passado de glória da casa onde, acredita-se, há décadas atrás "Todo mundo [do Borgerhout] esteve pelo menos uma vez" (DE ROMA, A UNIQUE... p.2, tradução nossa).

\section{Salas de cinema como lugares de memória}

A instrumentalização da(s) memória(s) dos cinemas e seus frequentadores geralmente aparece infiltrada em projetos de reabertura de salas exibidoras. Cremos que basicamente ela se vale de redes narrativas produzidas em torno das representações de cinemas antigos, tais como: 1) espaços quase perdidos, em busca de salvaguarda ou 
renascimento; 2) enclaves urbanos, dispositivos heterotópicos ${ }^{4}$ por excelência ligados à produção do sonho, a um outro tempo-espaço que se difere do vai-e-vem das calçadas; 3 ) e, sobretudo, local entrelaçado a uma gama variada de fortes reminiscências pessoais e grupais, o que não deixa de provocar manifestações de nostalgia.

Nas conceituações sobre a ideia de sala de cinema, é interessante citarmos o que Anette Kuhn (2002), uma das fundadoras do New Cinema History, diz sobre a íntima relação entre os prédios dos cinemas e os espectadores-transeuntes em seus trajetos diários. Em seu trabalho sobre os hábitos de ida ao cinema na Grã-Bretanha durante a década de 1930, a autora recorre ao pensamento de Michel de Certeau sobre práticas sociais e vida cotidiana para analisar as conversas que realizou com espectadores idosos. Kuhn se detém a observar o discurso produzido por ex-frequentadores de cinema a respeito de suas experimentações do espaço urbano há tempos atrás, quando eles ainda eram jovens e criavam trajetos rumo às salas de exibição das regiões onde moravam. Levando em conta que tais espectadores-transeuntes, nomeados por Kuhn como "cinemagoers" (2002, p. 35), se encaixam na figura de exímios praticantes da cidade/do espaço vivido, a autora destaca a maneira pela qual Certeau acentua as diferenças entre "nãopertencimento" e "pertencimento" a um lugar: o primeiro termo indica a existência de distâncias bem marcadas entre o observador e o objeto observado, onde uma forma de voyeurismo estaria em jogo; enquanto isso, o segundo termo refere-se à ideia de que "(...) pertencer a um lugar implica uma conexão somática, sensual, mesmo tática com ele" (KUHN, 2002, p. 35, tradução nossa).

Kuhn comenta que durante as entrevistas realizadas em seu trabalho de etnografia histórica ("ethno-history") - termo usado pela Antropologia Cultural do qual ela diz se apropriar (KUHN, 2002, p.

4 Aqui nos referimos à noção de espaço heterotópico foucaultiano, isto é, um espaço-outro, "uma espécie de contestação simultaneamente mítica e real do espaço em que vivemos (...)" (FOUCAULT, 1984, p.416). Michel Foucault menciona o cinema entre diversos tipos de heterotopia. Ele fala especificamente da sala de cinema, limitando-se ao arranjo interior do equipamento, dizendo que "o cinema é uma sala retangular muito curiosa, no fundo da qual, sobre uma tela em duas dimensões, vê-se projetar um espaço em três dimensões" (Idem). 
6) -, quando os interlocutores acionavam seus mapas de memórias pessoais, na maioria das vezes, os cinemas eram representados como "pontos de parada dentro do familiar", peças referenciais inseridas em meio a trajetos, feitos na escala do pedestre, entre a casa e a grande tela. Ela enfoca um ponto relevante: tais percursos, beneficiados pela disponibilidade de salas de cinema, imprimiram-se na memória corporal dos espectadores/transeuntes. Para a autora, um sentimento de pertença associado à conexão trajeto-cinema-espectadores/ transeuntes é evidenciado nos relatos dos interlocutores, ainda que o cerne familiar dos trajetos que eles executavam, conforme pondera Kuhn, fosse sempre interrompido por "uma excursão virtual para espaços não familiares, para outros mundos oferecidos pela tela do cinema" (KUHN, 2002, p. 6, tradução nossa).

Como profícuos locais ligados a múltiplos afetos e emoções, os cinemas se foram, mas de alguma maneira continuaram presentes nas impressões que as pessoas guardaram de seus caminhos, práticas e vivências no espaço construído das cidades. Diante disso, ao pensamos acerca dos cinemas reabertos, que parecem se valer das marcas deixadas por uma gama de experiências precedentes, percebemos que eles se apresentam como elementos estratégicos para a preservação de um passado latente, que, por razões diversas, precisará ser lembrado e revelado.

Cremos que a noção de sala de cinema reaberta se aproxima, em algum grau, do conceito de "lugares de memória" de Pierre Nora (1984). Apesar de discordarmos de que o projeto do De Roma exercite uma nostalgia paralisadora, de ode restrita ao passado, e mesmo indo de encontro à opinião de que este equipamento seja hoje um "empreendimento de piedade, patético e glacial", tal como Nora adjetiva alguns "lugares de memória", ainda assim, o conceito é válido para examinarmos o conjunto de fatores que se erguem em torno da recuperação do ex-cinema, um espaço intrinsecamente ligado a situações de apagamento de rituais e hábitos de cinema-going característicos de outras épocas. 
Estes lugares de memória são fundamentalmente vestígios do passado, as últimas encarnações de uma consciência da memória que sobrevive numa época histórica que não recorre à memória, pois a abandonou. Eles aparecem em virtude da desritualização de nosso mundo - produzindo, manifestando, estabelecendo, construindo, decretando e mantendo artificialmente e intencionalmente uma sociedade profundamente absorvida em sua própria transformação e renovação, que invariavelmente valoriza o novo em detrimento do antigo, o jovem em lugar do velho, o futuro em relação ao passado. Museus, arquivos, cemitérios e coleções, festas, aniversários, tratados, processos verbais, monumentos, santuários, associações, são os marcos testemunhas de uma outra era, das ilusões de eternidade. Daí os aspectos nostálgicos desses empreendimentos de piedade, patéticos e glaciais. São os rituais de uma sociedade sem ritual; sacralizações passageiras numa sociedade que dessacraliza; (...) Os lugares de memória nascem e vivem do sentimento que não há memória espontânea, que é preciso criar arquivos, que é preciso manter aniversários, organizar celebrações, pronunciar elogios fúnebres, notariar atas, porque essas operações não são naturais (NORA, 1984, p.12)

Acompanhando esse pensamento, é mister observarmos que os cinemas de rua em geral frequentemente desempenham o papel de marcos visuais, isto é, são elementos urbanos pontuais nas passagens das pessoas nas ruas. Além disso, funcionam como verdadeiras landmarks na elaboração das identidades locais e paisagens urbanas, a despeito do fenômeno transnacional de seu desaparecimento indiscriminado ocorrido em pequenas e grandes cidades durante os últimos 30, 35 anos. A imagem e o valor simbólico dos prédios que abrigaram cinemas se conservam nas histórias e nos afetos pessoais e na carne da cidade como um souvenir.

Embora faça parte de outro contexto de análise, lembramos a observação de Gilles Deleuze sobre o fato de que as cidades mantêm relações com a história das mídias (DELEUZE, 1992). A partir disso, sugerimos que as rupturas e continuidades transcorridas ao longo das épocas no cerne da cultura cinematográfica acompanham o próprio desenvolvimento de determinado local urbano, conectando-se a outras esferas da vida coletiva e das configurações citadinas. Se o equipamento cinema de rua, nos moldes em que se apresentou até o final do século $X X$, não reina mais como um ponto referencial urbano e opção de 
lazer soberana, é porque, claramente, as mídias, seus mercados e o acesso ao audiovisual cinematográfico encontraram outros suportes e caminhos; da mesma forma, os rituais de espectação cinematográfica - que, por sua vez, se conectam às práticas cotidianas efetivadas nos (novos) espaços - ganham outros arranjos. Quiçá por conta do impacto de todas essas transformações, uma onda de apreço pelo resgate de salas de cinema outrora marcantes torna-se, aqui e ali, a tônica de mobilizações da sociedade civil e instâncias governamentais, com ou sem o apoio do capital privado.

É este vigor da sala de cinema, como um dispositivo resistente e um "espaço do sonho" (VIEIRA e PEREIRA, 1982) atado fortemente às lembranças e aos universos afetivos das pessoas, aquilo que anima muitos projetos de reabertura, os quais se valem direta ou indiretamente da figura potente desses extintos/antigos movie theatres. Ao prefaciar o livro Ciné-Journal de Serge Daney, Deleuze (1992) coloca a questão da conservação de um suplemento, um souvenir que o cinema teria condições de criar. Por mais que Deleuze não se dirija neste texto aos equipamentos sala de cinema, mas à imagem cinematográfica, sua noção de souvenir torna-se pertinente para nós porque indica que o cinema, em todos os seus aspectos, tem a capacidade de preservar algo, uma centelha que pode ser ativada ou seguir em latência, a depender das circunstâncias.

Queremos justamente ir ao encontro desta dimensão suplementar que só o cinema seria capaz de preservar. Aliado ao meio urbano, o cinema, enquanto "equipamento coletivo de lazer", e a imagem cinematográfica, este "outro mundo" oferecido pelo ecrã, parecem se conservar de modo muito profundo nas reminiscências dos espectadores (FERRAZ, 2014). Mesmo quando são extirpados da paisagem onde estão incrustados, em algum grau, os cinemas e as ressonâncias dos filmes que exibiram mantêm laços com os indivíduos e comunidades, sustentam-se como pontos referenciais, ainda que imaginados, no sentido de que "Quando uma história, um sinal ou um significado vêm ligar-se a um objeto, aumenta o seu valor enquanto marco" (LYNCH, 
1999, p. 90).

As casas de exibição reabertas são elementos que fazem parte de uma rede mobilizada de memórias ligadas à fase de preponderância dos cinemas de rua entre os meios midiáticos de massa. Em um sentido próximo ao que Michael Pollak dá ao termo "memória enquadrada", como alternativa ao conceito de "memória coletiva", percebemos que a rede de memórias pessoais e grupais concernentes aos antigos cinemas é acionada e organizada segundo imperativos do presente.

A memória, essa operação coletiva dos acontecimentos e das interpretações do passado que se quer salvaguardar, se integra, como vimos, em tentativas mais ou menos conscientes de definir e de reforçar sentimentos de pertencimento e fronteiras sociais entre coletividades de tamanhos diferentes (...). É portanto absolutamente adequado falar, como Henry Rousso, em memória enquadrada, um termo mais específico do que memória coletiva. Quem diz 'enquadrada' diz 'trabalho de enquadramento'. Todo trabalho de enquadramento de uma memória de grupo tem limites, pois ela não pode ser construída arbitrariamente. Esse trabalho deve satisfazer a certas exigências de justificação (POLLAK, 1989, p. 9).

Investidores e entusiastas da reativação de equipamentos de exibição cinematográfica parecem manejar muito bem esse sentido. Remissões às eras de ouro de antigos cinemas, por exemplo, são dados que não deixam de fazer parte de um trabalho de enquadramento da memória. Assim, uma série de medidas são tomadas no tocante à recuperação desses locais segundo formatações e imperativos do presente, embora o passado cinematográfico nem sempre regresse com força entre as atividades dos novos espaços pós-reabertura. Esses são pontos que podem ser notados no caso do cine De Roma, que analisaremos a seguir.

\section{"More than just a cinema": o teatro popular De Roma}

Com base em dados coletados entre maio e novembro de 2015 ao longo de um trabalho de campo que contou com entrevistas e observação participante, além de informações obtidas em pesquisas 
em arquivos, cremos que o caso do cine De Roma, localizado no distrito do Borgerhout, na Antuérpia, região da Comunidade Flamenga belga, revela aspectos peculiares em relação aos usos instrumentais da memória e à intensa mobilização dos afetos de antigos frequentadores em prol da recuperação deste equipamento de lazer.

Inaugurado em 1928 por um imigrante italiano, o De Roma caracterizou-se desde cedo como um cinema de bairro e um centro de encontros para a população do distrito do Borgerhout. A força deste equipamento se deve a alguns fatos passados em relação aos laços criados com a população local, como, por exemplo, a decisão de JeanBaptiste Romeo, o fundador do De Roma, de ceder as instalações do cinema para que a própria comunidade do Borgerhout realizasse atividades culturais livres por lá uma vez por semana. Com espetáculos de palco e tela, o espaço teve uma importância capital para os lazeres locais, chegando a entrar na lista das poucas casas de exibição cinematográfica belgas autorizadas a funcionar durante a ocupação nazista, entre 1940 e 1945, desde que só exibissem produções alemães.

O De Roma foi também um cinema lançador. Apesar de ser distrital, praticamente restrito às dimensões urbanas de um bairro, e estando relativamente distante das zonas comerciais e do centro histórico/ turístico da Antuérpia, sua programação englobava lançamentos de fitas hollywoodianas sem atrasos em relação aos cinemas mais centrais. Isso passou a ocorrer principalmente a partir de 1953, quando a administração da casa ficou a cargo de Georges Heylen, um "barão" do mercado exibidor belga que integrou o De Roma ao seu vasto circuito de salas comerciais, o grupo Rex. Sessões de estreia de filmes estadunidenses como "When the Redskins Rode" (1951) e "The Clown" (1953), por exemplo, aparecem nos registros dos arquivos do De Roma como grandes sucessos da casa de exibição. Produções belgas "arrasaquarteirão" também foram exibidas pelo De Roma: as sessões do filme "De bruid zonder bed" (1955), de Edith Kiel, alcançaram um público de 11 mil pessoas neste cinema (DE ROMA, A UNIQUE..., p.6), cerca de $2 \%$ de toda a população da região da Antuérpia naquela fase. 
Porém, uma fase de baixas de público mudaria os rumos do De Roma. Durante uma densa transformação sociocultural ocorrida no distrito do Borgerhout ${ }^{5}$, a administração do De Roma precisou encontrar alternativas contra uma crise na bilheteria. A partir da década de 1960, o Borgerhout foi ocupado por imigrantes mulçumanos, essencialmente marroquinos, que imigraram para trabalhar na Antuérpia durante o período pós-Segunda Guerra Mundial (MUSLIMS IN ANTWERP, 2011, p. 18). Segundo Rob Gielen, atual assessor de comunicação do De Roma, devido às fortes diferenças dos hábitos culturais e de lazer dos grupos imigrantes, e também por causa da evasão das audiências belgas locais, houve uma expressiva queda na frequentação do equipamento ${ }^{6}$. Sobre isso, ele comenta:

\begin{abstract}
No começo dos anos 70, tivemos a combinação de dois fatores que provocaram o início da queda de visitantes. 0 primeiro foi o aparecimento da TV a cabo. Esse foi um fator importante para as pessoas não virem mais para o cinema e ficarem em casa. Outro fator, talvez mais importante, se deve à grande mudança demográfica do distrito. Ele costumava ser um espaço muito católico e jovem, mas durante os anos de crise, a população jovem migrou para o centro da Antuérpia. Assim, muitas casas foram colocadas à venda e ao mesmo tempo muitos imigrantes do Marrocos e da Turquia vieram morar no Borgerhout, principalmente marroquinos. Agora estamos em 2015, então, há 50 anos atrás o governo belga assinou um tratado com a Turquia e o Marrocos permitindo que os imigrantes viessem trabalhar aqui. Atualmente, 0 Borgerhout é o distrito mais denso em população e mistura de nacionalidades. Eles não têm ou não tinham a cultura de ir ao cinema. Eles não participam de atividades públicas de lazer. Esse tipo de atividade não concerne às suas próprias comunidades. Essa é uma diferença porque nós vamos a atividades coletivas de lazer e eles, não. Esses são os dois fatores, TV e transições demográficas, que contribuíram para o declínio do De Roma.
\end{abstract}

A sangria nas frequências fez com que o grupo Rex modificasse o tipo de atividade central operada no espaço. Contra um fechamento

\footnotetext{
5 O distrito do Borgerhout é composto por dois largos bairros, o Borgerhout Intramuros e o Borgerhout Extramuros, que possuem estruturas populacionais distintas. O primeiro concentra uma população de origem belga menor, sendo ocupado predominantemente por imigrantes mulçumanos, principalmente vindos do Marrocos. Há ainda turcos na composição populacional do bairro. O interessante é que por conta da característica fortemente marroquina do local, o Borgerhout ganhou a alcunha de Borgerocoo em referência ao vasto efetivo de cidadãos com raízes no Marrocos (MUSLIMS IN ANTWERP, 2011, p. 18). 6 Dados coletados durante entrevista com Rob Gielen em maio de 2015.
} 
imediato, o De Roma passou a funcionar como casa de shows e acabou se transformando em um os mais respeitáveis palcos da Bélgica por algum tempo. Artistas como Paul McCartney, James Brown e Iggy Pop chegaram a se apresentar no local. Entretanto, a falência não tardou muito a chegar e o equipamento cerrou definitivamente as portas em 1982. Foram 20 anos de abandono, com uma avassaladora deterioração da fachada e das estruturas internas do cinema, além de atos de vandalismo contra o prédio e itens deixados no seu interior como, por exemplo, os projetores, que foram destruídos ou saqueados.

Após o edifício ter sido comprado por um investidor privado em 1993 - que não teve interesse em reabrir o local para nenhuma atividade e o manteve em estado de degradação -, em 1997 um centro cultural do Borgerhout, o Rataplan, alugou o primeiro andar do prédio para a realização de pequenas atividades culturais em meio aos escombros. Em 2002, uma força-tarefa de voluntários começou a reconstruir o De Roma, retirando entulhos e fazendo os reparos do que ainda podia ser salvo. Em 2003, o cinema foi reinaugurado como um teatro popular, com capacidade para 2.000 pessoas.

A programação hoje é sortida e basicamente focada em shows musicais e peças de teatro, mas há sessões cinematográficas que acontecem pelo menos uma vez ao mês, dando preferência a filmes de arte e ensaio belgas ou estrangeiros. Além disso, o De Roma exerce uma considerável influência na agenda cultural da Antuérpia e se coloca como um equipamento bastante participativo na vida sociocultural e política do distrito do Borgerhout e da cidade como um todo.

Esta participação ativa do De Roma na comunidade se deve muito ao tipo de gestão do equipamento. O De Roma é um espaço gerenciado por uma associação sem fins lucrativos, que fora criada em 2002 justamente para dar suporte à reabertura do equipamento. Com $100 \%$ de controle da parte financeira das operações, a associação De Roma vzw é responsável pela administração dos aportes injetados pelos governos da província da Antuérpia (nível local), da cidade da Antuérpia, da Comunidade Flamenga, do distrito do Borgerhout, 
além das subvenções vindas do Fundo Europeu de Desenvolvimento Regional, que juntos representam 30\% das receitas do equipamento.

Porém, não foram os recursos governamentais que aprovisionaram a fase inicial de reerguimento do De Roma. A retomada cultural do espaço só ocorreu devido à devoção de parte da população local do Borgerhout, admiradores do cinema e antigos frequentadores. Foram eles que, de forma voluntária, fizeram as primeiras restaurações do prédio do extinto cinema e, do mesmo modo, elaboraram o projeto de reativação. Até hoje, o trabalho voluntário no dia-a-dia do De Roma é um aspecto indispensável para a sua sobrevivência. Ao lado de um pequeno corpo de funcionários assalariados, os voluntários atuam em diversas frentes: no bar, na cozinha, na bilheteria, na limpeza, na organização do hall de entrada etc.

A rede de mobilização em prol do De Roma, para além do caso das ações de voluntariado e dos recursos públicos advindos das políticas culturais da região flamenga e administrações locais da Antuérpia, incluem ainda algumas medidas que possibilitam investimentos particulares no equipamento. Existe um menu de esponsorização à disposição de empresas e também de pessoas que admiram o trabalho realizado pelo De Roma. Qualquer indivíduo pode fazer doações diretas para o equipamento via website (nos valores de 5, 15, 25 e 35 euros) ou, por exemplo, adotar cadeiras em processo de restauro. O projeto do De Roma ainda oferece ao público, principalmente aos idosos que frequentavam o cinema no passado, um programa de inclusão do equipamento como beneficiário de testamentos.

A ideia de antigo cinema de bairro é aplicada em favor deste modelo atual do De Roma, que não se caracteriza mais como um cinema convencional. O seu passado como cinema de rua tornouse uma das fontes de recurso e justificativa para a conquista de entusiastas, voluntários e investidores de variados níveis. Baseado em narrativas sobre este passado cinematográfico (e o período como casa de shows), o projeto do De Roma construiu uma série de conceitos ligados aos esforços empregados em prol da recuperação/manutenção 
do espaço. É através do conceito de "Nós somos De Roma" ("We are De Roma") e do uso de palavras-chaves como "acreditar", "ter esperança", "sonhar" ("believe", "hoping" e "dreaming") (DE ROMA, A UNIQUE..., p.4) que se efetivam todas as ações da vida cultural do equipamento, a sensibilização do público e a renovação do prédio e seus elementos, levando em conta a sua inserção na cidade e na comunidade intercultural do Borgerhout:

Nós somos De Roma - Isto é um conceito, um trabalho de vida que nunca terá fim. Continuamos a trabalhar com o mesmo entusiasmo e a mesma devoção. Continuamos a acreditar, a ter esperança, a sonhar. Acreditando numa cidade habitável e agradável, onde as pessoas se encontrem e vivam experiências em comum. Tendo esperança de que o espírito positivo do De Roma encoraje iniciativas similares no Borgerhout. Sonhando que nós podemos estimular as pessoas a saírem de seu isolamento para aproveitarem uma performance no De Roma, no De Roma delas. Desejamos a cada pessoa um futuro cheio de respeito, compreensão e tolerância, mas também cheio de momentos de emoção no De Roma ou em outros de nossos teatros (...). Desejamos que todas as autoridades se disponham a dar uma chance justa a todos os tipos de cultura. Por fim, desejamos para nós mesmos um futuro brilhante com nada mais do que rostos felizes e sem problemas financeiros (DE ROMA, A UNIQUE..., p.4, tradução nossa).

As narrativas oficiais do De Roma engendradas em face de seu passado e de suas vocações contemporâneas vêm em socorro de um sentido preservacionista daquilo que já esteve à beira de um apagamento irremediável. Tzvetan Todorov fala a respeito desta interação entre o apagamento e a luta pela conservação do passado, relacionando essas expressões à noção de memória. "A memória não se opõe absolutamente ao esquecimento. Os dois termos contrastantes são o apagamento (o esquecimento) e a conservação; a memória é, sempre e necessariamente, uma interação entre os dois" (TODOROV, 2004, p.14). Em outro momento, Todorov também destaca que certos pontos de referência são capazes de estruturar a nossa memória, incluindo-a na memória coletiva da qual fazemos parte. Nessa análise, ele cita tanto Pierre Nora quanto Maurice Halbwachs quando descreve os marcos referenciais como monumentos, lugares de memória e 
instrumentos que reforçam a coesão social?.

Posto isso, não podemos deixar de notar que as falas oficiais do De Roma se dirigem visivelmente a questões vinculadas à inserção do equipamento no Borgerhout e a operações de afirmação identitária fortemente ligadas a um passado de predominância belga/flamenga naquela região. Nesse ponto, é válido recorrermos em linhas gerais ao conceito de "memória manipulada" de Paul Ricoeur, cuja especificidade está situada "no cruzamento entre a problemática da memória e da identidade tanto coletiva como pessoal" (RICOEUR, 2004, p.80).

No seio da ideia de "memória manipulada" - que corresponde ao nível prático dos três tipos de usos e abusos da memória natural classificados pelo autor $^{8}$-, está a previsão de que existe um intenso trabalho das relações de poder em manipular memória e esquecimento. Este campo de forças é o lugar onde são engendrados alguns abusos da memória, criações de versões interessadas e autorizadas, seleções do que deve ser lembrado e do que deve ser esquecido. Nesse âmbito, Ricoeur salienta que é impossível separarmos memória e identidade, pois a mobilização da memória está a serviço dos apelos e demandas da identidade, o que, grosso modo, passa pela legitimação de determinados sistemas de poder e por circunscrições da memória de acordo com os traços identitários que definem determinada comunidade ( $p .85$ ).

Podemos, assim, inferir que a rede discursiva amparada por narrações sobre o passado histórico do De Roma como um antigo cinema de importância fundamental para a vida das pessoas e do Borgerhout participam deste jogo de lembrança-esquecimento e fomentam a produção de uma memória coletiva sobre o espaço. No entorno das

\footnotetext{
7 Pollak destaca a diferença entre a perspectiva de Halbwachs e a consideração que estudos construtivistas fazem acerca da memória coletiva. Para o autor, Halbwachs dá especial atenção à ideia de uma memória coletiva não coercitiva, capaz de unir os indivíduos em comunidades afetivas, apesar de reconhecer que há negociações entre a memória coletiva e as memórias individuais. Por outro lado, a perspectiva construtivista irá se interessar em como se constituem e se formalizam as memórias, quem são os atores e quais são os processos legitimadores que agem nessas construções. Esses trabalhos reconhecerão que há silenciamentos, seletividades e memórias que muitas vezes são apagadas em favor de uma memória hegemônica (POLLAK, 1989).

8 Ricoeur classifica três tipos de usos e abusos da memória natural: "memória impedida" (nível patológicoterapêutico), "memória manipulada" (nível prático) e "esquecimento de reserva" ou "memória obrigada" (nível ético-político) (RICOEUR, 2004, p.68-92).
} 
manifestações em prol de sua manutenção atual como teatro popular, também parece haver seleções estratégicas do que deve ser lembrado e em razão de quê. Por exemplo, a já mencionada questão do De Roma ter sido um dos únicos cinemas belgas a continuar funcionando durante a ocupação nazista, exibindo somente fitas alemães (cujas sessões no De Roma, de acordo com o assessor de comunicação do equipamento, Rob Gielen, obtinham boas audiências) é um dado pouco encontrado em meio ao material oficial organizado pela direção do projeto. Entre os usos estratégicos de sua representação como cinema e, decorrente desta memória como antigo cinema, há nuances e lacunas em relação a outros fatos, tais como a sua transição de cinema de bairro gerido por um grupo familiar para um espaço integrado ao império comercial do barão Georges Heylen.

As hipóteses que lançamos sobre o enquadramento estratégico da memória e a legitimação de determinadas versões do passado do De Roma se conectam ao que os autores ligados ao paradigma New Cinema History propõem sobre a história social da instituição cultural cinema. Segundo essa perspectiva, a história do cinema - pensado como uma instituição atravessada por uma miríade de vetores que não se limitam a questões cinematográficas propriamente ditas - lida com variadas ordens que passam por aspectos econômicos, o mercado de filmes em geral, estratégias corporativas de todos os tipos, mecanismos de censura e ainda com a micro história das práticas de ida ao cinema em níveis locais, o que, por sua vez, incluirá a história sociocultural das próprias audiências, seus padrões de gosto, orientações políticas, gênero, faixa etária, poder aquisitivo etc.

Se há determinadas formas de contar sobre o passado de um cinema em vista de interesses pontuais do presente, não há como negar que tais enquadramentos, manipulações e construções da memória dizem respeito a esferas associadas às formas locais de organização social, lazer, dinâmicas da política cultural, entre outros vetores. Esse argumento corresponde à expectativa da corrente New Cinema History de atrelar o campo do cinema ao que há de mais contextual, ou melhor, 
ao cotidiano e às miudezas que ingressam na experiência densa da ida ao cinema.

\section{Um espaço de exercício da memória: breves notas finais}

Devemos ter em mente que os anos de funcionamento do De Roma como cinema, antes de sua atividade como casa de espetáculos musicais, correspondem à outra estruturação sociocultural do Borgerhout. Conforme vimos, com a entrada das comunidades árabes na região, outros vetores identitários passaram o atravessar o distrito. Por mais que tenha havido um rompimento dos laços entre o cinema e as práticas de lazer locais durante os 20 anos de inatividade do equipamento, esse abismo não apagou definitivamente as reminiscências e os vestígios do De Roma. Ao contrário, foi desta espécie de "luto produtivo", da recusa em esquecer, que os atos pela sua recuperação se efetivaram.

Para Maurice Halbwachs (1992), a memória coletiva estará sempre ancorada em marcos espaciais que nos oferecem uma imagem de permanência e estabilidade. Hoje, o De Roma assume esta postura de lugar de memória em busca de uma estabilidade para as identidades e pertencimentos a ele vinculados, tal como seu projeto parece indicar:

\footnotetext{
Por que o De Roma causa tantas emoções mais do que outros espaços $(. .$.$) ? Porque ele é um 'espaço de memória' (...), um$ espaço que abraça a memória de várias gerações (...). Para as pessoas idosas, o De Roma é uma mera memória viva que de repente ressuscitou. Dezenas e dezenas de voluntários arregaçaram as mangas e alcançaram um sonho impossível. A restauração é um projeto fantástico concretizado pelas pessoas e isso é bastante singular. Após anos de frustração e infelicidade, todas as ruas em torno do De Roma levantaram e contribuíram para a reativação do De Roma. Noções como idealismo, pioneirismo e solidariedade ganharam um novo significado (DE ROMA, A UNIQUE..., p.2, tradução nossa).
}

Acreditamos que o caso do De Roma se vincula à noção de que a memória coletiva corresponde a formas de vida social que no passado marcaram os espaços urbanos e sobreviveram a mudanças, ganhando 
novos contornos e significados no presente (JODELET, 2010). Entre esses novos contornos, encontram-se mobilizações estratégicas em prol da manutenção do De Roma como um marco cultural regional e também aspectos que revelam o forte vínculo entre o equipamento e instâncias estatais.

O De Roma chega a ser considerado por alguns atores sociais como uma importante peça para as táticas de governamentalidade e influência política da Comunidade Flamenga belga e lideranças locais da Antuérpia no território. Recentemente, o equipamento esteve envolvido em embates políticos relativos à configuração das vias expressas que cortam a Antuérpia. Por ter cedido o seu espaço para a realização das reuniões do grupo que é a favor das obras de renovação do trânsito, as lideranças de um partido contrário, o separatista N-VA, acusaram o De Roma de ter se tornado um espaço policizado. Segundo o N-VA, o posicionamento político do De Roma em assuntos gerais da cidade contraria as suas finalidades como espaço cultural, cuja natureza deve ser neutra, já que o equipamento recebe recursos públicos advindos da administração pública (WYCKMANS, 2015). Contrariando este ponto de vista, conforme vimos, todo o processo de reativação do De Roma - que se mostra como um espaço de exercício da memória - envolveu desde o começo a sua acentuada participação no cenário sociopolítico e cultural do Borgerhout e, numa escala mais ampla, da Antuérpia.

Diante de todos esses aspectos, o caso belga do De Roma serve como um largo exemplo para que outros episódios de reabertura de cinemas possam ser examinados à luz do New Cinema History ou simplesmente por pesquisadores interessados em ir ao encalço das performances que tais equipamentos (em nada neutros) desempenham na configuração dos espaços das cidades relacionados às mídias, nos domínios sociocultural, político e econômico urbanos e na produção de sociabilidades, afetos e memórias dos indivíduos. Há de se levar em conta que as bordas do cinema, instituição social, são sempre porosas; mais ainda, é preciso perceber os projetos de reabertura ou reestruturação de históricas salas de cinema em vista das táticas de 
gestão das culturas urbanas locais e memórias das audiências, que, conforme o caso do De Roma demonstra, são suscitadas em prol de interesses e pautas fomentados por uma miríade agentes.

\section{Referências bibliográficas}

BILTEREYST, Daniël; MALTBY, Richard; MEERS, Philippe. Cinema, audiences and modernity: an introduction. In: BILTEREYST, Daniël; MALTBY, Richard; MEERS, Philippe (orgs.). Cinema, audiences and modernity: new perspectives on European cinema history. Oxon, New York: Routledge, 2012.

CENTRE DU CINÉMA ET DE L'AUDIOVISUEL. Bilan de la production 2014, Bélgica, 2015. Disponível em: http://www.audiovisuel.cfwb.be/index. php?id=avm_bilancca. Acesso em: 15 jul. 2015.

DE ROMA WEBSITE. Desenvolvido pelo teatro De Roma. Apresenta informações sobre o teatro. Disponível em: http://www.deroma.be . Acesso em: 15 jul.2015.

DE ROMA, A UNIQUE HISTORY. Antuérpia: De Roma, s/d, 10 p. Relatório técnico.

DELEUZE, Gilles. Conversações. Trad.: Peter Pál Pelbart. São Paulo: Editora 34, 1992.

FERRAZ, Talitha. A segunda Cinelândia carioca. Rio de Janeiro: Mórula, 2012.

- Espectação Cinematográfica no subúrbio carioca da Leopoldina: dos 'cinemas de estação' às experiências contemporâneas de exibição. 2014. 235f. Tese (Doutorado em Comunicação e Cultura) - Escola de Comunicação da UFRJ. Universidade Federal do Rio de Janeiro, Rio de Janeiro.

FOUCAULT, Michel. Space, knowledge and power. In: RABINOW, Paul (Ed.). The Foucault Reader. New York: Pantheon Books, 1984.

HALBWACHS, Maurice. A memória coletiva. São Paulo: Vértice, 1990.

JODELET, Denise. La memoria de los lugares urbanos. Alteridades, vol. 20, n. 39, jan-jun, 2010, pp. 81-89. Universidad Autónoma Metropolitana Iztapalapa, Distrito Federal, México. Disponível em: http://www.redalyc.org/ src/inicio/ArtPdfRed.jsp?iCve=74720828007. Acesso em: 3 out, 2015.

KUHN, Annette. An everyday magic: cinema and cultural memory. London: I.B. Tauris \& Co, 2002.

LYNCH, Kevin. A imagem da cidade. Trad.: Jefferson Luiz Camargo. São Paulo: Martins Fontes, 1999. 
LOTZE, Kathleen e MEERS, Philippe. 'They don't need me in heaven... There are no cinemas there, ye know': cinema culture in Antwerp (Belgium) and the empire of Georges Heylen, 1945-75. In: AVEYARD, K. e MORAN, A. (orgs.). Watching films: new perspectives on movie-going, exhibition and reception. Bristol; Chicago: Intelect, 2013.

MALTBY, Richard. New Cinema Histories. In: MALTBY, Richard; BILTEREYST, Daniël; MEERS, Philippe. Explorations in New Cinema History: approaches and case studies. Oxford: Blackwell Publishing, 2011.

MALTBY, Richard; BILTEREYST, Daniël; MEERS, Philippe. Explorations in new cinema history: approaches and case studies. Oxford: John Wiley \& Sons, 2011.

NORA, Pierre. Les lieux de mémoire. Paris: Gallimard, 1984.

MUSLIMS IN ANTWERP. At Home in Europe Project. London: Open Society Foundation, 2011.

POLLAK, Michael. Memória, esquecimento, silêncio. Estudos Históricos, Rio de Janeiro, v.2, n.3, p.3-15, 1989.

PORTAL BELGIUM.BE. Governo Federal da Bélgica, 2012. Apresenta dados sobre a Bélgica. Disponível em: http://www.belgium.be. Acesso em: 3 out. 2015.

RICOEUR, Paul. Memory, History, Forgetting. Trad.: Kathleen Blamey e David Pellauer. Chicago, London: The University Chicago Press, 2004.

STATISTICS BELGIUM. Cinémas. Bélgica, 2014. Disponível em: http:// statbel.fgov.be/fr/statistiques/chiffres/travailvie/temps/cinema/. Acesso em: 10 jul. 2015.

STEUN DE ROMA WEBSITE. Apresenta informações para os investidores do teatro De Roma. Disponível em: http://www.steunderoma.nu/ . Acesso em: 15 jul. 2015.

TODOROV, Tzvetan. Les abus de la mémoire. Paris: Arléa, 2004.

VIEIRA, João Luiz e PEREIRA, Margareth Campos da Silva. Espaços do sonho: arquitetura dos cinemas no Rio de Janeiro 1920-1950. Rio de Janeiro: Embrafilme, 1982.

WYCKMANS, Ferre. Subsidie Is Geen Zwijggeld - Cultuur Is Niet Neutraal, Ook Niet in De Roma. De Standaard, Antuérpia, 27 mar. 2015. Disponível em: http://www.standaard.be/cnt/dmf20150326_01600810. Acesso em: 30 mar. 2015. 